\title{
Patient profiles and outcomes of lymphoma patients who underwent autologous stem cell transplant in National Kidney and Transplant Institute: a single-center analysis
}

\author{
Danielle Francesca Leonardo, Jose Roberto Amparo
}

Department of Internal Medicine-Medical Oncology, National Kidney and Transplant Institute, Manila, Philippines

Background: Autologous stem cell transplantation (ASCT) is the standard of care for relapsed or refractory lymphoma for over 50 years and is associated with better overall survival compared to those who received chemotherapy alone. In the Philippines, no study has been done among lymphoma patients who received ASCT and their corresponding outcomes. The National Kidney and Transplant Institute (NKTI) pioneered stem cell transplantation in the Philippines in 1990; however, transplantation in lymphoma started only in 2019. This is the first local study to review ASCT outcomes among lymphoma patients.

Methods: This is a retrospective review in a single-institution of adult lymphoma patients who underwent ASCT from February 2019 to December 2020 in NKTI.

Results: There were eight adult lymphoma patients who received ASCT from February 2019 to December 2020. Most patients (seven of eight) were diagnosed with Hodgkin lymphoma and all had relapsed/refractory disease with at least two lines of treatment received prior. All patients received BeEAM (bendamustine, etoposide, cytarabine, melphalan) protocol as conditioning regimen. Neutrophil engraftment was observed after an average of 11.4 days and patients were discharged on an average 16.2 days after transplantation. One patient died during admission, one patient still has not yet been re-evaluated, one patient relapsed, and five patients remained in remission, the longest duration being 2 years.

Conclusions: ASCT can be safely and successfully performed in this institution. Immediate outcomes are comparable to global data; however, longer-term follow-up is recommended to further determine its durability in terms of disease control and survival in the local setting.

Corresponding author: Danielle Francesca Leonardo

E-mail: danielleleonardo@gmail.com

This is an Open Access article distributed under the terms of the Creative Commons Attribution Non-Commercial License (http://creativecommons.org/licenses/by-nc/4.0/) which permits unrestricted non-commercial use, distribution, and reproduction in any medium, provided the original work is properly cited. 